\title{
Prevalence of Helicobacter pylori Infection in Military Personnel from Northeast China: A Cross-Sectional Study
}

\author{
Chunmei Wang ${ }^{1,2, *}$ \\ Jun $\mathrm{Liu}^{3} *$ \\ Xiaoye Shi' \\ Shaoze Ma' \\ Guangqin $\mathrm{Xu}{ }^{\prime}$ \\ Tingwei Liu' \\ Tingting $\mathrm{Xu}^{3}$ \\ Bo Huang ${ }^{3}$ \\ Ying $\mathrm{Qu}^{4}$ \\ Xiaozhong Guo' \\ Xingshun Qi $\mathbb{D}^{\prime}$
}

'Department of Gastroenterology, General Hospital of Northern Theater

Command (Formerly General Hospital of Shenyang Military Area), Shenyang, People's Republic of China; ${ }^{2}$ Graduate School, Jinzhou Medical University, Jinzhou, People's Republic of China; ${ }^{3}$ Military Joint Teaching and Research Office, The 32684 Troop of Chinese PLA, Shenyang, People's Republic of China; ${ }^{4}$ Department of Health Care, General Hospital of Northern Theater Command (Formerly General Hospital of Shenyang Military Area), Shenyang, People's Republic of China

*These authors contributed equally to this work

Correspondence: Xingshun Qi;

Xiaozhong Guo

Department of Gastroenterology, Genera Hospital of Northern Theater Command (Formerly General Hospital of Shenyang Military Area), No. 83 Wenhua Road, Shenyang, Liaoning Province, I 10840 ,

People's Republic of China

Tel +86-24-28897603

Fax +86-24-2885 I I I3

Email xingshunqi@I26.com;

guo_xiao_zhong@I26.com
Purpose: Helicobacter pylori infection is an important cause of peptic ulcer disease and gastric cancer. Current knowledge regarding epidemiology of $H$. pylori infection in military personnel has insufficiently been updated. This cross-sectional study aimed to estimate the prevalence of $H$. pylori infection in military personnel and to compare the prevalences in military and civilian groups.

Patients and Methods: We retrospectively enrolled the subjects who underwent ${ }^{14} \mathrm{C}$-urea breath tests at the Department of Gastroenterology of the General Hospital of Northern Theater Command between January 2017 and July 2020. Subjects were divided into military and civilian groups. H. pylori infection and major endoscopic findings were reviewed.

Results: Overall, 23,496 subjects were eligible, including 2282 subjects in the military group and 21,214 subjects in the civilian group. In the overall analysis, the prevalence of $H$. pylori infection was not significantly different between military and civilian groups $(33.9 \%$ versus $34.4 \%, P=0.592$ ). In the population aged $17-25$ years, the prevalence of $H$. pylori infection was significantly higher in the military group than in the civilian group $(35.6 \%$ versus $25.9 \%, P=0.001$ ). Both ${ }^{14} \mathrm{C}$-UBT and endoscopy were performed in 547 inpatients, including 83 military inpatients and 464 civilian inpatients. There was a significantly higher prevalence of $H$. pylori in inpatients with peptic ulcer and/or gastric cancer than in those without $(65.5 \%$ versus $41.4 \%, P=0.001)$.

Conclusion: Among the adolescent population, H. pylori infection may be more common in military personnel as compared to the civilians. Well-designed prospective studies should be required to validate such a high prevalence and to explain its potential causes.

Keywords: Helicobacter pylori, prevalence, military, epidemiology, endoscopy

\section{Introduction}

Helicobacter pylori infection is one of the most common bacterial infections in humans. ${ }^{1}$ The prevalence of $H$. pylori infection varies around the world. The $H$. pylori infection rate is about $50.8 \%$ in developing countries as compared to $34.7 \%$ in developed countries. ${ }^{2}$ Such a variation is dependent upon society and geographic location, and is affected by environmental factors, socio-demographic characteristics, socio-economic status, health habits and population lifestyles. ${ }^{3,4}$ Risk factors of $H$. pylori infection include age, smoking, drinking, socioeconomic status and living environment. ${ }^{5-8}$ It has been widely confirmed that $H$. pylori infection is associated with chronic active gastritis, peptic ulcer disease, gastric 
adenocarcinoma and mucosa-associated lymphoid tissue lymphoma. $^{9-11}$ It has been categorized as a Class I carcinogen according to the World Health Organization. ${ }^{12}$

Military personnel are the most powerful guarantors for safeguarding the territorial integrity of the country and for protecting the people to live and work in the country. Physical and mental health is of particular importance for such a unique population. However, they often suffer from chronic mental and physical health conditions, ${ }^{13,14}$ because they have to experience highpressure military and survival training in extremely harsh environments. This will reduce humoral and cellular immune responses and may aggravate the severity of H. pylori infection. ${ }^{15}$ In addition, military personnel often endure great pressures from personal development, interpersonal relationships and family and economic situations. ${ }^{16}$ As a result, military personnel may have a higher risk of $H$. pylori infection. ${ }^{17}$

Knowledge regarding the epidemiology of $H$. pylori infection in military personnel is of great significance to guide in preventing $H$. pylori infection and decreasing its related diseases, thereby improving the combat effectiveness of the army. However, until now, the evidence on the prevalence of $H$. pylori infection in military personnel is scare. Herein, the purpose of the present cross-sectional study was to determine the prevalence of $H$. pylori infection in military personnel from Northeast China and to compare the prevalences in the military and civilian groups.

\section{Methods}

\section{Study Design}

We retrospectively analyzed the data of ${ }^{14} \mathrm{C}$-urea breath test (UBT) performed at the Department of Gastroenterology of our hospital from January 2017 to July 2020. Exclusion criteria were as follows: 1) disintegrations per minute (DPM) values for ${ }^{14} \mathrm{C}$-UBT tests were lacking; 2) medical records were lacking; 3 ) subjects had a definite history of $H$. pylori eradication; and 4) repeated ${ }^{14} \mathrm{C}$-UBT tests were performed in the same subject. We primarily collected the information regarding demographics (ie, age and gender), subjects' identity (ie, military or civilian) and history of $H$. pylori eradication. Identity of eligible subjects could be clearly classified into military or civilian groups based on their unique ID number obtained from the electronic medical record system of our hospital. In the current study, military personnel mainly refers to active servicemen in the combat or non-combat army. Besides, some non-active senior officers who are still guaranteed by the army were also included in the military personnel group. Otherwise, civilians are defined.

\section{${ }^{14}$ C-UBT}

Subjects undergo ${ }^{14} \mathrm{C}$-UBT tests fasting or 2 hours after eating. Before the ${ }^{14} \mathrm{C}$-UBT test, subjects take one urea $\left[{ }^{14} \mathrm{C}\right]$ capsule $(27.8 \mathrm{kBq})$ with cold drinking water and remain relatively calm for 5 minutes. A bottle of $\mathrm{CO}_{2}$ gas collector is opened, and a clean gas duct with backflow prevention device is inserted. The lower end of the duct penetrates into the gas collector liquid, and the subjects blow air through the tube with moderate force. When the $\mathrm{CO}_{2}$ gas collector turns from purple to colorless, the subjects stop blowing (about 1-3 minutes). After the gas sample is collected, $4.5 \mathrm{~mL}$ diluted scintillation solution is added into the sample bottle with a clean pipette, and the bottle is sealed with a cap. The sample is dissolved and shaken well into the tester [HUBT-01P (Shen Zhen Shi Zhong He Hai De Wei Sheng Wu Ke Ji You Xian Gong Si)] for $H$. pylori detection. A diagnosis of $H$. pylori infection is based on the ${ }^{14} \mathrm{C}$-UBT result $\geq 100$ $\mathrm{DPM} / \mathrm{mmolCO}_{2}$.

\section{Upper Gastrointestinal Endoscopy}

We also collected the information regarding endoscopic and pathological findings for inpatients, mainly peptic ulcer and gastric cancer. Among the inpatients, the criteria for upper gastrointestinal endoscopy are mainly based on the patient's digestive symptoms, as well as the attending physicians' decisions and the patient's willingness.

\section{Statistical Analyses}

All statistical analyses were performed with IBM SPSS 20.0 (IBM Corp, Armonk, NY, USA) and Microsoft Office Excel 2010 software (Microsoft Corp, Redmond Washington, USA). Continuous variables were expressed as median (range). Categorical variables were expressed as frequency (percentage). Non-parametric Mann-Whitney $U$-test was used for continuous variables, and chi-square test was used for categorical variables to compare the prevalences in military and civilian groups. Subgroup analyses were performed according to the age, gender and endoscopic diagnosis. A two-sided $P<0.05$ was considered statistically significant. 


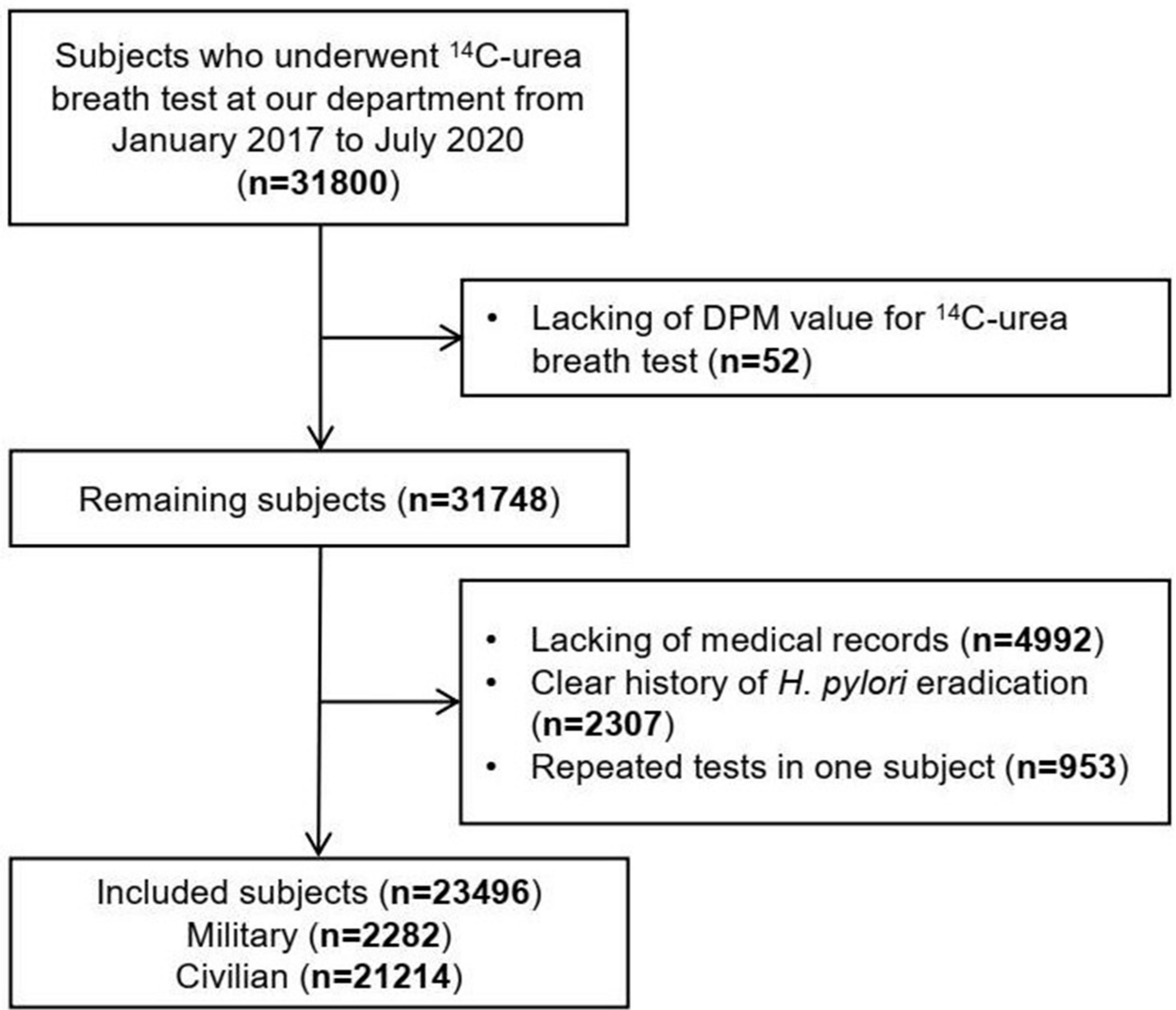

Figure I A flowchart of subject inclusion.

\section{Results}

\section{Subject Characteristics}

During the study period, there were a total of $31,800{ }^{14} \mathrm{C}$-UBT records. Among them, 8304 records were excluded, because 52 subjects were lacking the DPM values for ${ }^{14} \mathrm{C}-\mathrm{UBT}$; 4992 subjects were lacking medical records; 2307 subjects had a definite history of $H$. pylori eradication; and 953 subjects had repeated ${ }^{14} \mathrm{C}$-UBT tests. Finally, 23,496 subjects were eligible, including 2282 military subjects and 21,214 civilian subjects (Figure 1). The median age of the military group was 36.00 years (range: $17.00-96.00)$; and $87.29 \%$ (1992/2282) were male. The median age of civilian group was 51.00 years (range: 8.00-94.00); and 44.25\% $(9387 / 21,214)$ were male.

\section{Prevalence of $H$. pylori Infection}

In the overall analysis, the prevalence of $H$. pylori infection was not significantly different between military and civilian groups $(33.9 \%$ [773/2282] versus 34.4\% [7305/ 21,214], $P=0.592$ ) (Figure 2).

In the male population, the prevalence of $H$. pylori infection was not significantly different between military and civilian groups (33.4\% [665/1992] versus 34.9\% [3272/ 9387], $P=0.209$ ). In the female population, the prevalence of $H$. pylori infection was not significantly different between military and civilian groups (37.2\% [108/290] versus 34.1\% [4033/11,827], $P=0.265$ ) (Figure 3).

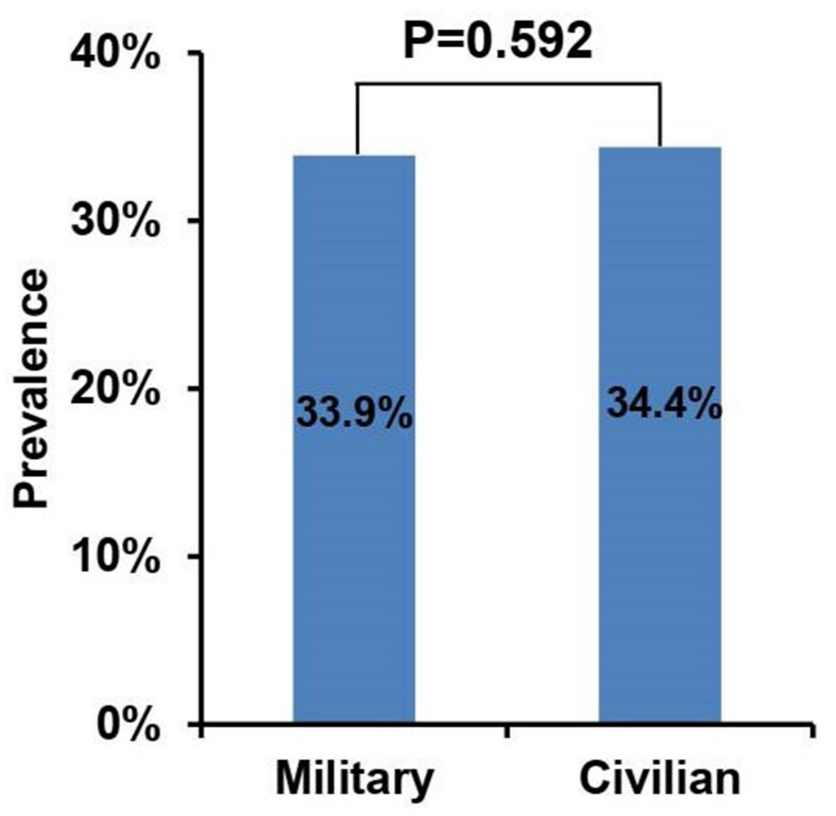

Figure 2 Overall analysis of the prevalence of Helicobacter pylori infection between military and civilian groups. 


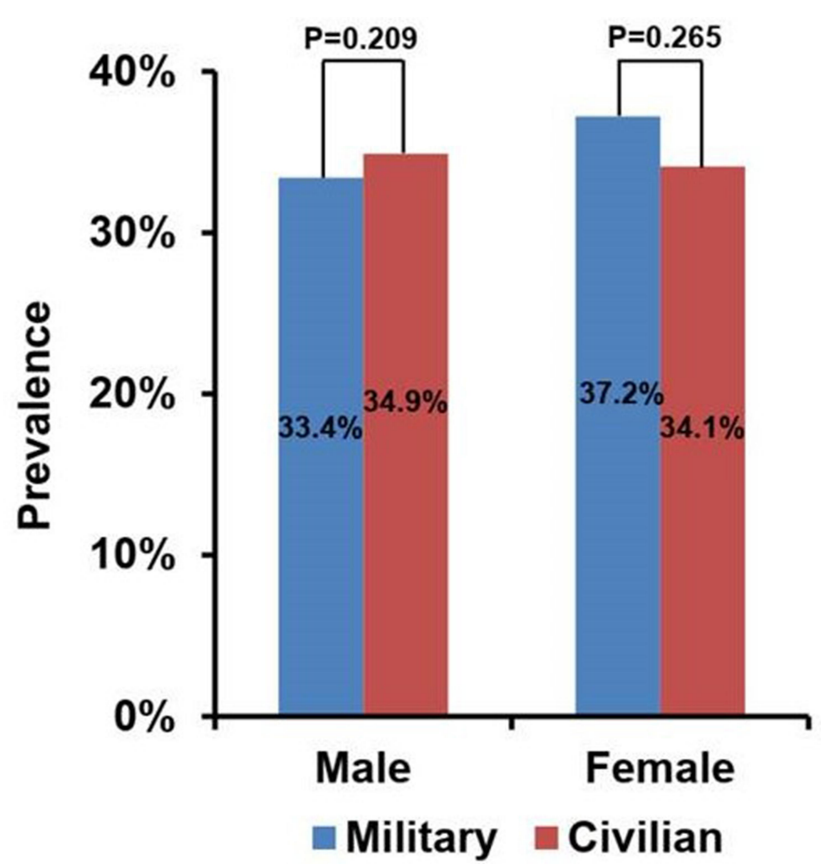

Figure 3 Gender analysis of the prevalence of Helicobacter pylori infection between military and civilian groups.

In the population aged 17-25 years, the prevalence of $H$. pylori infection was significantly higher in the military group than in the civilian group $(35.6 \%$ [94/264] versus $25.9 \%$ [281/1132], $P=0.001$ ) (Figure 4). However, in other age populations, the prevalence of $H$. pylori infection was not significantly different between military and civilian groups.

\section{Upper Gastrointestinal Endoscopy}

Five hundred and forty-seven inpatients, including 83 military inpatients and 464 civilian inpatients, underwent both ${ }^{14} \mathrm{C}$-UBT and upper gastrointestinal endoscopy. The median age of the military group was 48.00 years (range: 19.00-92.00); and 96.40\% (80/83) were male. The median age of the civilian group was 58.00 years (range: 17.0086.00); and 61.60\% (286/464) were male. Among them, the prevalence of $H$. pylori infection was $49.91 \%(273 /$ 547); the prevalence of peptic ulcer and/or gastric cancer was $35.47 \%$ (194/547), including 186 peptic ulcer and 8 gastric cancer. There was a significantly higher prevalence of $H$. pylori infection in inpatients with peptic ulcer and/or gastric cancer than in those without $(65.5 \%$ [127/194] versus $41.4 \%$ [146/353], $P=0.001)$.

The prevalence of peptic ulcer and/or gastric cancer was higher in the military group than in the civilian group, but the difference was not statistically significant $(44.6 \%$ [37/83] versus 33.8\% [157/464], $P=0.060)$. By contrast, the prevalence of peptic ulcer and/or gastric cancer was statistically similar between $H$. pylori positive military and civilian groups (43.5\% [20/46] versus 47.1\% [107/227], $P=0.650$ ) (Table 1).

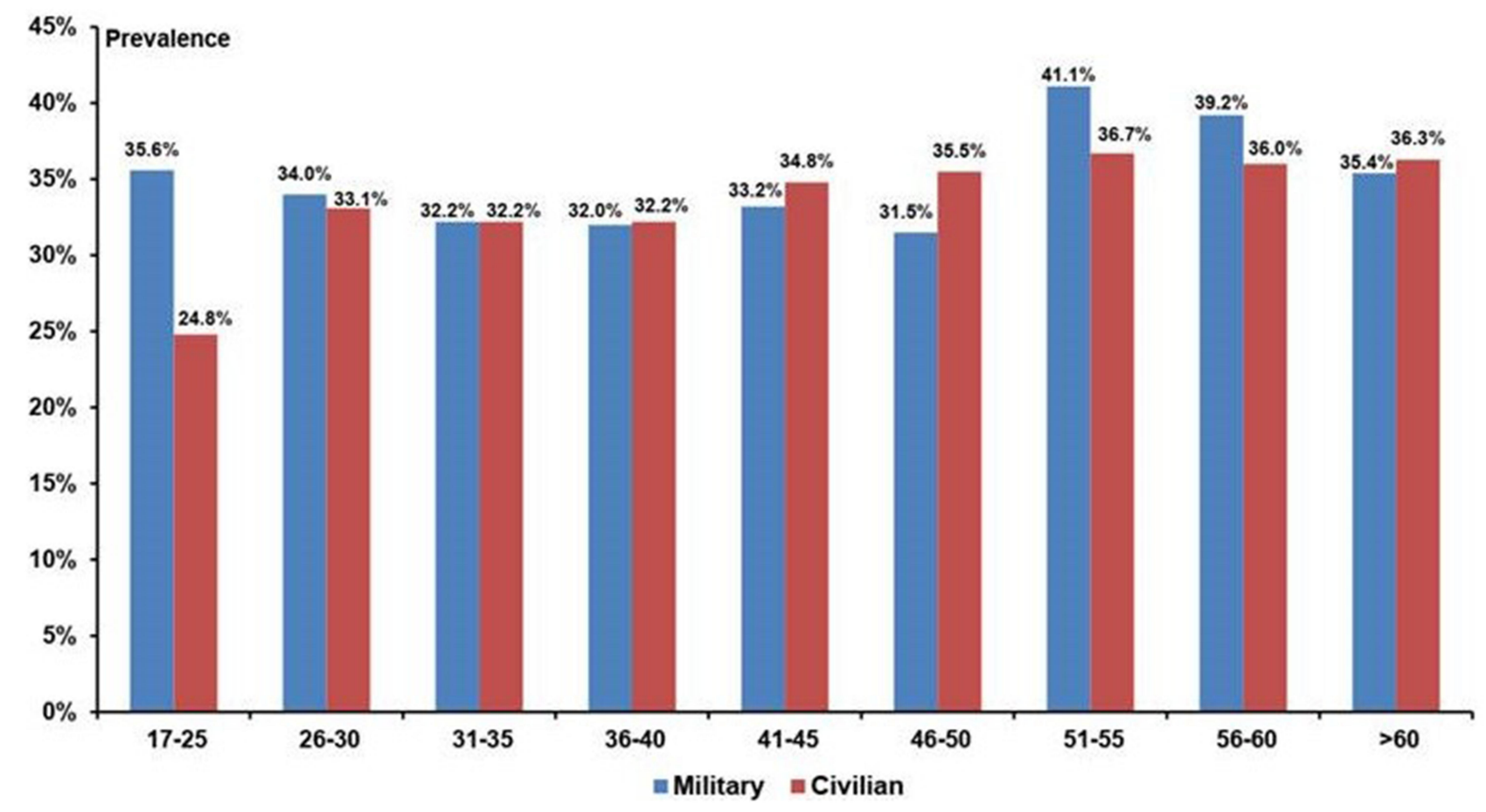

Figure 4 Age analysis of the prevalence of Helicobacter pylori infection between military and civilian groups. 
Table I Comparison of Prevalence of Peptic Ulcer and/or Gastric Cancer Between Military and Civilian Groups

\begin{tabular}{|c|c|c|c|c|c|}
\hline \multirow[t]{2}{*}{ Variables } & \multicolumn{2}{|c|}{ Military Group } & \multicolumn{2}{|c|}{ Civilian Group } & \multirow[t]{2}{*}{$P$ value } \\
\hline & No. Pts. & $\begin{array}{c}\text { Frequency } \\
\text { (Percentage) }\end{array}$ & No. Pts. & $\begin{array}{c}\text { Frequency } \\
\text { (Percentage) }\end{array}$ & \\
\hline Peptic ulcer and/or gastric cancer & 83 & $37(44.6 \%)$ & 464 & 157 (33.8\%) & 0.060 \\
\hline $\begin{array}{l}\text { Peptic ulcer and/or gastric cancer and } \\
\text { H. pylori positive }\end{array}$ & 46 & $20(43.5 \%)$ & 227 & 107 (47.1\%) & 0.650 \\
\hline
\end{tabular}

Abbreviations: Pts., patients; H. pylori, Helicobacter pylori.

\section{Discussion}

By using a relatively large population-based sample, we observed that the prevalence of $H$. pylori in the military personnel was $33.9 \%$, which was similar to that in our civilian participants (34.4\%). However, the prevalence was lower than that reported in previous Chinese studies. Among them, 510 air force personnel from the Chinese Southern Theater underwent serology antibody assessment and ${ }^{14} \mathrm{C}$-UBT, and the prevalence of $H$. pylori was $59.2 \% ;{ }^{18} 1649$ Chinese army and navy recruits underwent ${ }^{13} \mathrm{C}$-UBT, and the prevalence of $H$. pylori was $46.5 \% ;{ }^{19}$ 1293 Chinese army personnel underwent ${ }^{13} \mathrm{C}$-UBT, and the prevalence of $H$. pylori was $45.63 \%{ }^{20}$

Additionally, the prevalence of $H$. pylori infection varies among countries, which may be related to regional, ethnic and national socioeconomic conditions, ${ }^{21}$ and among armies which may be related to military environment, logistic equipment and sanitary conditions. Our prevalence was higher than that reported in other countries, where the $H$. pylori seropositive rate was $26.3 \%$ in US army recruits, ${ }^{22} 23 \%$ in Hungarian male recruits ${ }^{23}$ and $27.23 \%$ in Greek navy recruits. ${ }^{24}$

In the adolescent population, the prevalence of H. pylori infection was significantly higher in the military group than in the civilian group. This may be explained by the following. First, the recruits need to go through high-intensity military training, which is a psychologically and physically demanding process, for the purpose of achieving physical standards established by the army. ${ }^{25}$ Extensive military training can cause mental stress, ${ }^{26}$ which suppresses the body's humoral and cellular immunity and increases the risk of $H$. pylori infection. ${ }^{15}$ Second, lots of young soldiers live collectively in a barrack and share the same dormitory. ${ }^{27}$ Overcrowding, which is common in military communities, has been shown to be an important risk factor for $H$. pylori infection. ${ }^{28}$
We also found the prevalence of peptic ulcer and/or gastric cancer was higher in the military group than in the civilian group, which was consistent with previous findings, ${ }^{29}$ however, the prevalence of peptic ulcer and/or gastric cancer in the H. pylori positive military groups was lower than in the $H$. pylori positive civilian groups. This finding suggests that other causes, except for $H$. pylori infection, make more contributions to the development of peptic ulcer and/or gastric cancer in military personnel. Notably, our recent systematic review indicated that the 6 most important risk factors for peptic ulcer in military personnel were history of smoking, followed by high-intensity training, mental stress, family history of peptic ulcer, history of alcohol drinking and use of non-steroidal anti-inflammatory drugs. ${ }^{30}$

In this study, the ${ }^{14} \mathrm{C}-\mathrm{UBT}$ was used to detect the presence of $H$. pylori. It is noninvasive and has become increasingly more popular than invasive tests for the diagnosis of H. pylori infection. ${ }^{14} \mathrm{C}-\mathrm{UBT}$ has a high diagnostic accuracy for detecting $H$. pylori infections. ${ }^{31}$ It is able to detect current H. pylori infection, ${ }^{32}$ and is used to evaluate the efficacy of $H$. pylori eradication therapy. However, there are some limitations regarding the use of ${ }^{14} \mathrm{C}$-UBT. For example, a history of antibiotics use, proton pump inhibitors or bismuth may produce false negative results. ${ }^{33}$ In addition, the ${ }^{14} \mathrm{C}$-UBT is not recommended for use in children or pregnant women due to its radioactivity. ${ }^{31}$

There are some other limitations in our study. First, some subjects' information cannot be accurately traced by the electronic medical records, and then they have been excluded. Second, the history of $H$. pylori eradication has not been sufficiently reviewed. Third, there is a difference in the sample size between military and civilian groups. Fourth, we cannot distinguish the difference in the prevalence of $H$. pylori infection between combat and non-combat military personnel.

In conclusion, H. pylori infection is common in the military personnel from Northeast China, especially in the adolescent population. Therefore, we should strengthen 
the screening of $H$. pylori in such populations in the future. Additionally, considering the negative impact of $H$. pylori infection, the risk factors for $H$. pylori infection should be further identified, and its effective prevention and treatment strategy should be established.

\section{Abbreviations}

H. pylori, Helicobacter pylori; UBT, urea breath test; DPM, disintegrations per minute.

\section{Ethics Approval and Informed Consent}

The study protocol has been approved by the Medical Ethical Committee of the General Hospital of Northern Theater Command with an approval number [Y (2021) 018] and performed according to the Declaration of Helsinki. Due to the nature of this retrospective observational study without any additional interventions, patients' informed consents were exempted. All personally identifiable records are kept confidential.

\section{Disclosure}

The authors report no conflicts of interest in this work.

\section{References}

1. Cave DR. Transmission and epidemiology of Helicobacter pylori. Am J Med. 1996;100(5a):12S-17S. doi:10.1016/S0002-9343(96)80224-5

2. Zamani M, Ebrahimtabar F. Systematic review with meta-analysis: the worldwide prevalence of Helicobacter pylori infection. Aliment Pharmacol Ther. 2018;47(7):868-876. doi:10.1111/apt.14561

3. Olokoba AB, Gashau W, Bwala S, Adamu A, Salawu FK. Helicobacter pylori infection in Nigerians with dyspepsia. Ghana Med J. 2013;47(2):79-81.

4. Tanih NF, Dube C, Green E, et al. An African perspective on Helicobacter pylori: prevalence of human infection, drug resistance, and alternative approaches to treatment. Ann Trop Med Parasitol. 2009;103(3):189-204. doi:10.1179/136485909X398311

5. van Blankenstein $M$, van Vuuren AJ, Looman CW, Ouwendijk M, Kuipers EJ. The prevalence of Helicobacter pylori infection in the Netherlands. Scand J Gastroenterol. 2013;48(7):794-800. doi: 10.3109/00365521.2013.799221

6. Hanafi MI, Mohamed AM. Helicobacter pylori infection: seroprevalence and predictors among healthy individuals in Al Madinah, Saudi Arabia. J Egypt Public Health Assoc. 2013;88(1):40-45. doi:10.1097/ 01.EPX.0000427043.99834.a4

7. Ueda J, Gosho M, Inui Y, et al. Prevalence of Helicobacter pylori infection by birth year and geographic area in Japan. Helicobacter. 2014;19(2):105-110. doi:10.1111/hel.12110

8. Lim SH, Kwon JW, Kim N, et al. Prevalence and risk factors of Helicobacter pylori infection in Korea: nationwide multicenter study over 13 years. BMC Gastroenterol. 2013;13:104. doi:10.1186/1471230X-13-104

9. Asano N, Iijima K, Koike T, Imatani A, Shimosegawa T. Helicobacter pylori-negative gastric mucosa-associated lymphoid tissue lymphomas: a review. World $J$ Gastroenterol. 2015;21(26):8014-8020. doi:10.3748/wjg.v21.i26.8014
10. Huang T, Lee C. Diagnosis, treatment, and outcome in patients with bleeding peptic ulcers and Helicobacter pylori infections. Biomed Res Int. 2014;2014:658108. doi:10.1155/2014/658108

11. Huang JQ, Sridhar S, Chen Y, Hunt RH. Meta-analysis of the relationship between Helicobacter pylori seropositivity and gastric cancer. Gastroenterology. 1998;114(6):1169-1179. doi:10.1016/ S0016-5085(98)70422-6

12. Sepulveda AR. Helicobacter, Inflammation, and Gastric Cancer. Curr Pathobiol Rep. 2013;1(1):9-18. doi:10.1007/s40139-013-0009-8

13. Chou HW, Tzeng WC, Chou YC, et al. Stress, Sleep and Depressive Symptoms in Active Duty Military Personnel. Am J Med Sci. 2016;352(2):146-153. doi:10.1016/j.amjms.2016.05.013

14. Hurst S, Maiya M, Casteel D, et al. Yoga therapy for military personnel and veterans: qualitative perspectives of yoga students and instructors. Complement Ther Med. 2018;40:222-229. doi:10.1016/j.ctim.2017.10.008

15. Jia K, An L, Wang F, et al. Aggravation of Helicobacter pylori stomach infections in stressed military recruits. J Int Med Res. 2016;44(2):367-376. doi:10.1177/0300060515593768

16. Gewirtz A, DeGarmo D, Zamir O. Testing a Military Family Stress Model. Fam Process. 2018;57(2):415-431. doi:10.1111/ famp. 12282

17. Pak K, Junga Z, Mertz A, Singla M. The patterns and associated cost of serologic testing for helicobacter pylori in the U.S. Military Health System. Mil Med. 2020;185(9-10):e1417-e1419. doi:10.1093/ milmed/usaa141

18. Jiang HL, Chen FW, Xia XL, et al. Prevalence of and risk factors for Helicobacter pylori infection in Chinese military personnel. World Chin J Digestol. 2013;21(36):4084-4091. doi:10.11569/wcjd.v21. i36.4084. Chinese.

19. Yu J, An H, Su H, et al. [Risk factors associated with Helicobacter pylori infection in army and navy recruits]. Zhonghua Yi Xue Za Zhi. 2015;95(2):138-141. Chinese.

20. Li SJ, Fang S, Jin P, et al. Investigation on psychological status and its relationship with Helicobacter pylori infection in servicemen from a Chinese army unit. Med J Chin People Lib Army. 2017;42 (2):172-176. Chinese.

21. Sasidharan S, Uyub A, Azlan A. Further evidence of ethnic and gender differences for Helicobacter pylori infection among endoscoped patients. Trans $R$ Soc Trop Med Hyg. 2008;102 (12):1226-1232. doi:10.1016/j.trstmh.2008.05.006

22. Smoak BL, Kelley PW, Taylor DN. Seroprevalence of Helicobacter pylori infections in a cohort of US Army recruits. Am J Epidemiol. 1994;139(5):513-519. doi:10.1093/oxfordjournals.aje.a117034

23. Furesz J, Lakatos S, Nemeth K, Fritz P, Simon L, Kacserka K. The prevalence and incidence of Helicobacter pylori infections among young recruits during service in the Hungarian Army. Helicobacter. 2004;9(1):77-80. doi:10.1111/j.1083-4389.2004.00200.x

24. Kyriazanos ID, Sfiniadakis I, Gizaris V, et al. The incidence of Helicobacter pylori infection is not increased among obese young individuals in Greece. J Clin Gastroenterol. 2002;34(5):541-546. doi:10.1097/00004836-200205000-00012

25. Psaila M, Ranson C. Risk factors for lower leg, ankle and foot injuries during basic military training in the Maltese Armed Forces. Physical Therapy in Sport. 2017;24:7-12. doi:10.1016/j. ptsp.2016.09.004

26. King LA. Risk factors for mental, physical, and functional health in Gulf War veterans. J Rehabilitation Res Dev. 2008;45(3):395-408. doi:10.1682/JRRD.2007.06.0081

27. Shinchi K, Ishii H, Imanishi K, Kono S. Relationship of cigarette smoking, alcohol use, and dietary habits with Helicobacter pylori infection in Japanese men. Scand J Gastroenterol. 1997;32 (7):651-655. doi:10.3109/00365529708996513

28. Galpin O, Whitaker C, Dubiel A. Helicobacter pylori infection and overcrowding in childhood. Lancet. 1992;339(8793):619. doi:10.1016/0140-6736(92)90907-K 
29. Hayashi T, Ohrui N, Kobayashi M, Ohashi K, Ikeda T. Peptic ulcer data from 4 years of endoscopy in 955 pilots of the Japan Air Self Defense Force. Aviat Space Environ Med. 2003;74(10):1067-1071.

30. Wang C, Guo X, An Y, et al. Risk factors of peptic ulcer in military personnel: a systematic review of the literature. Explor Res Hypothesis Med. 2020;5(3):103-109.

31. Zhou Q, Li L, Ai Y, Pan Z, Guo M, Han J. Diagnostic accuracy of the C-urea breath test in Helicobacter pylori infections: a meta-analysis. Wien Klin Wochenschr. 2017;129:38-45. doi:10.1007/s00508-0161117-3
32. Ricci C, Holton J, Vaira D. Diagnosis of Helicobacter pylori: invasive and non-invasive tests. Best Pract Res Clin Gastroenterol. 2007;21 (2):299-313. doi:10.1016/j.bpg.2006.11.002

33. Patel S, Pratap C, Jain A, Gulati A, Nath G. Diagnosis of Helicobacter pylori: what should be the gold standard? World Journal of Gastroenterology. 2014;20(36):12847-12859. doi:10.3748/wjg.v20.i36.12847
International Journal of General Medicine

\section{Publish your work in this journal}

The International Journal of General Medicine is an international, peer-reviewed open-access journal that focuses on general and internal medicine, pathogenesis, epidemiology, diagnosis, monitoring and treatment protocols. The journal is characterized by the rapid reporting of reviews, original research and clinical studies across all disease areas. The manuscript management system is completely online and includes a very quick and fair peer-review system, which is all easy to use. Visit http://www.dovepress.com/ testimonials.php to read real quotes from published authors. 